\title{
Uncertainty, Cost-effectiveness and Environmental Safety of Robust Carbon Trading: Integrated Approach
}

\author{
Tatiana Ermolieva (emol@iiasa.ac.at) \\ Yuri Ermoliev (ermoliev@iiasa.ac.at) \\ Matthias Jonas (jonas@iiasa.ac.at) \\ Michael Obersteiner (oberstei@iiasa.ac.at) \\ Fabian Wagner (wagnerf@iiasa.ac.at) \\ Wilfried Winiwarter (winiwart@iiasa.ac.at)
}

\section{Approved by}

Pavel Kabat

IIASA Director/Chief Executive Officer

15 July 2013 Institute, its National Member Organizations, or other organizations supporting the work. 


\section{Contents}

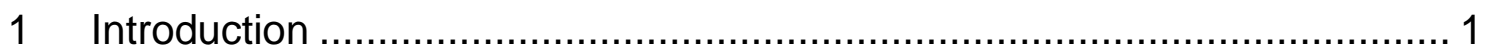

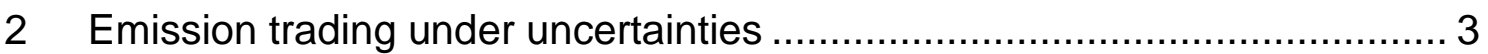

3 Stochastic model for robust emission trading .......................................... 7

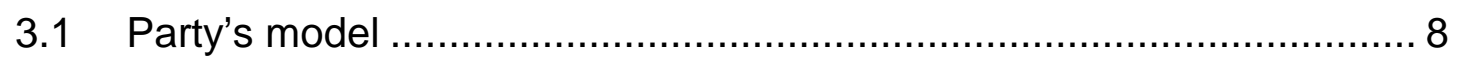

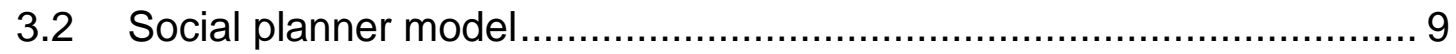

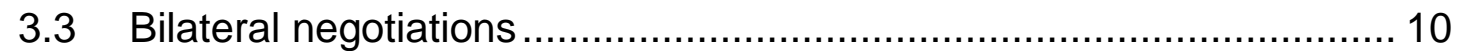

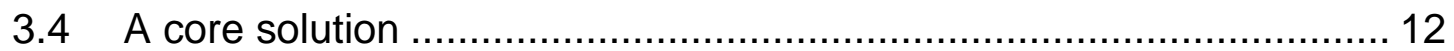

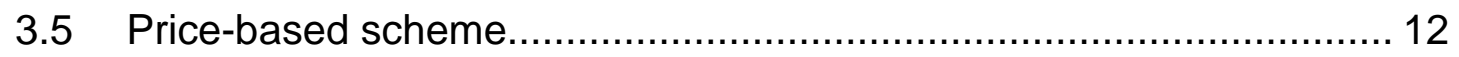

4 Computerized Multi-Agent Trading System: Numerical Experiments........ 13

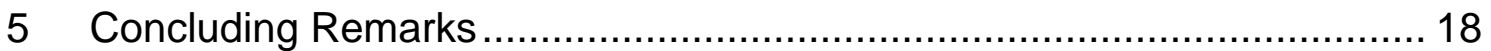

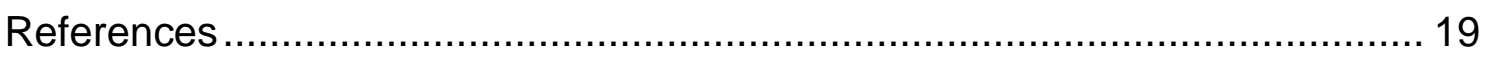




\section{Abstract}

The emission trading scheme was devised to lower the cost of achieving greenhouse gas emission reductions: emissions are reduced where it is cheapest and emission certificates are then traded to meet the nominal targets for each participant. However, carbon markets, like other commodity markets, are volatile. They react to stochastic “disequilibrium" spot prices, which may be affected by inadequate policies, speculations and bubbles. The market-based emission trading, therefore, does not necessarily minimize abatement costs and achieve emission reduction goals. We introduce a basic stochastic trading model allowing to analyze the robustness of emission reduction policies under asymmetric information and other multiple anthropogenic and natural uncertainties. We illustrate functioning of the robust market with numerical results involving such countries as US, Australia, Canada, Japan, EU27, Russia, Ukraine. In particular, we analyze if the knowledge about uncertainties may affect portfolios of technological and trade policies or structure of the market and how uncertainty characteristics may affect market prices and change the market structure. 


\section{About the Authors}

Dr. Tatiana Ermolieva is a Research Scholar with the Ecosystems Services and Management Program at IIASA. Among her main research topics are analysis and modeling of complex socioeconomic, agricultural, environmental, and financial systems with explicit treatment of uncertainties, risks and extreme events; robust down- and upscaling methods for land use planning under climate change uncertainties and risks; robust economic instruments for climate change mitigation and adaptation.

Prof. Dr. Yuri Ermoliev is a IIASA Institute Scholar and contributes his research to the Advanced Systems Analysis (ASA) Program at IIASA. Dr. Ermoliev's research concerns stochastic optimization methods and models, robust solutions, path-dependent adaptation processes, pollution control problems, energy and agriculture modeling, reliability theory, optimization of discontinuous systems subject to abrupt changes and catastrophic risks, endogenous discounting in climate change projects, approaches for robust food-water-energy security management.

Dr. Matthias Jonas is a Senior Research Scholar with the Ecosystems Services and Management Program at IIASA. His research concerns the uncertainty in greenhouse gas cycles and the development of systems analytical models and tools to address issues of global, universal and regional change, including surprises, and their potential implications for decision and policy-makers.

Dr. Michael Obersteiner is Leader of the Ecosystems Services and Management Program at IIASA. Dr. Obersteiner's research experience stretches from biophysical modeling in the areas of ecosystems, forestry and agriculture to environmental economics, bioenergy engineering, climate change sciences, management of catastrophic risks, novel approaches to learning and discounting in long-term climate change related projects.

Dr. Fabian Wagner is a Senior Research Scholar in the Mitigation of Air Pollution \& Greenhouse Gases (MAG) Program, IIASA. Dr. Wagner's expertise ranges from integrated assessment modeling covering energy, socio-economic, biophysical and chemical dimensions, to the economics of climate change mitigation and co-benefit analysis. He has developed the optimization modules of the GAINS/RAINS model family, which have been used in a number of policy applications in Europe and Asia for designing clean air and greenhouse gas mitigation policies. 
Prof. Dr. Wilfried Winiwarter is a Senior Research Scholar with the MAG program at IIASA. Prof. Winiwarter's interest in systems analysis derives from the overarching challenges of climate research. Originally an atmospheric scientist and specializing in the release of trace compounds into the atmosphere, he quantified current and potential future emissions of greenhouse gases. Integrating nitrous oxide in the GAINS model, he became interested in investigating global biogeochemical cycles, specifically the nitrogen cycle. The interaction between physical and social systems and their respective interferences now also serves as a major focus of his work. 


\section{Uncertainty, Cost-effectiveness and Environmental Safety of Robust Carbon Trading: Integrade Approach}

Tatiana Ermolieva,Yuri Ermoliev, Matthias Jonas, Michael Obersteiner, Fabian Wagner and Wilfried Winiwarter

\section{Introduction}

The main goal of this report is to analyze robust cost-effective and environmentally safe carbon trading programs under asymmetric (private) information about cost functions and other natural and human-created uncertainties.

Economic instruments for environmental regulations become popular both among policy-makers and scientific communities (Stavins 2010). Prominent examples of adopted economic instruments for the management of air pollution and $\mathrm{CO}_{2}$ reduction are emissions cap and trade programs (de Jong and Walet 2004; Kerr 2000). These programs are now a key element in climate change policy negotiations. Emission trading has established carbon prices as a new currency and emission permits as a new asset type (Kerr 2000).

In theory, the emission price of tradable allowances (permits) should establish the marginal cost of emissions reductions to meet the cap. In reality, the prices exhibit periods of high volatility which may be a result of political decisions, information disclosure, speculations, bubbles, uncertainties around emissions and emissions reduction costs. For example, from January to April 2006, carbon prices went down from $€ 26 / \mathrm{tCO}_{2}$ to $€ 10 / \mathrm{tCO}_{2}$ after the data for 2005 was verified and adjusted emission levels revealed (see Figure 1). Similarly, if not as abrupt, the recent crisis led to a dramatic decrease in carbon prices to about $€ 13 / \mathrm{tCO}_{2}$.

As studied by the Potsdam Institute for Climate Impact Research (Roos 2011), immaturity of the existing market policies triggered a major "dash for coal setting out on the construction of dozens of new coal plants. ...”. Also, in the Netherlands, “... $\mathrm{CO}_{2}$ emissions trading is a marginal consideration in the choice of fuel. Evidently, electricity producers are not too bothered about the price they pay for carbon emissions. The vast majority still favors coal, the worst carbon polluter. The reason is simple: the expected costs of emission rights are negligible compared to other investment outlays.” 
Building of coal-fired plants now, will lock-in further energy decisions for approximately forty years (Stikkelman et al. 2010).

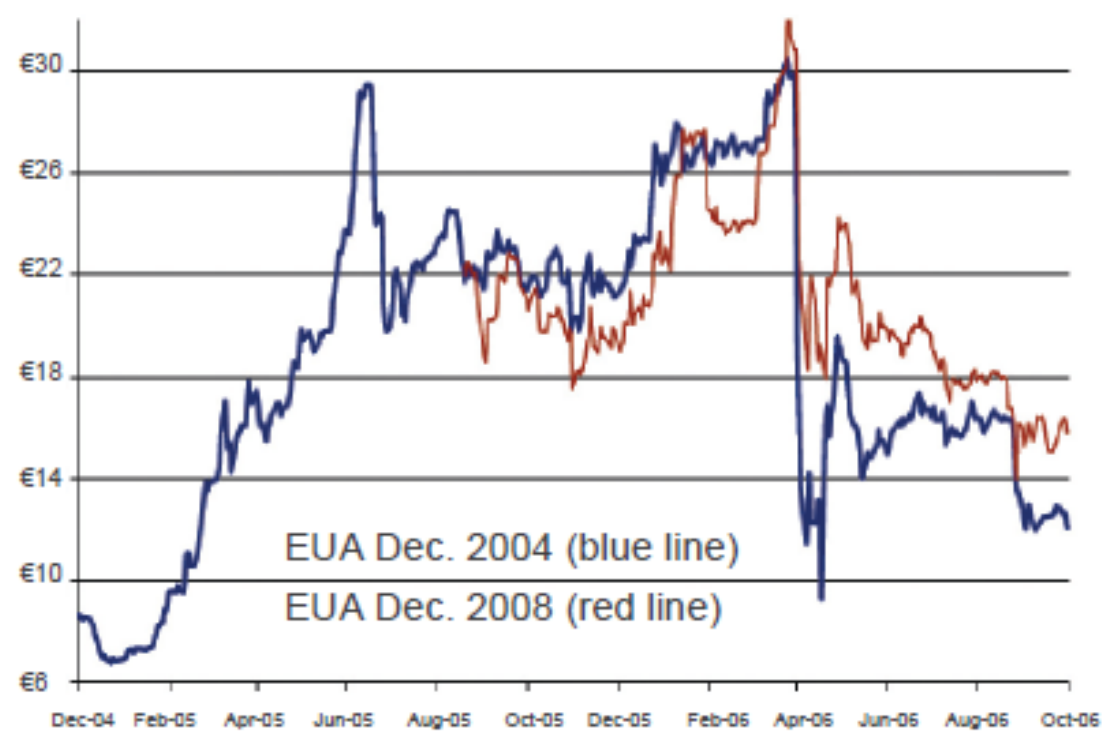

Figure 1. Source: www.pointcarbon.com (see also Betz 2006).

The short-term information from market spot prices gained in different years/periods (as shown in Section 2) may contradict and cause parties to revise their "myopic" decisions which, however, may not be reversible.

Lessons learned from the existing emission trading schemes point out to the need for market safety regulations smoothing its performance. In this report, we propose a computerized multiagent trading system (CMATS) which may function as a prototype of a real emission trading market without revealing the private information of parties about costs and emissions. The system may enhance/improve real markets by analyzing conditions for robust trades and stable market's performance. In particular, it allows the introduction of emissions uncertainty for dealing with long-term decisions perspectives, potential irreversibility and "lock-in" equilibriums. CMATS is designed as a multicomputer network of traders and can be viewed as a device for decentralized collective regulation of trades by helping individual parties in understanding how they can implement trades at the lowest risk-adjusted costs.

The report ${ }^{1}$ is organized as follows. Section 2 reviews the classical approach to emission trading and discusses its shortcomings under uncertainty. This section also discusses main sources of emissions uncertainty. In Section 3 a model for robust emission trading under uncertainty and incomplete information is analyzed. Section 4

\footnotetext{
${ }^{1}$ The report has been substantially restructured and its revised version is forthcoming in Climatic Change journal.
} 
outlines the structure of the CMATS and summarizes numerical results on trading involving such countries as US, Australia, Canada, Japan, EU27, Russia, Ukraine, etc. In this section we discuss how the knowledge about uncertainties may affect structure of the market, e.g., turn buyer into seller, and how new participants may improve or destabilize market's performance. Conclusions are presented in Section 5.

\section{Emission trading under uncertainties}

A key issue for developing cost-effective and environmentally safe emission reduction schemes is the private character of information. If emission reduction costs are known, then the problem is reduced to the standard social cost minimization model subject to environmental safety targets. The asymmetric private information on emission reduction costs requires developments of special decentralized emission reduction processes which can be viewed as emission trading schemes. The report analyses this type of trading processes.

Emission trading as an economic instrument for environmental regulations has been analyzed e.g. by Dales (1968). The author assumed that environmental agency requires each regulated source to submit a permit (also known as a quota, credit, or allowance) for each unit of pollution emitted. These permits are transferable. Each source reduces its emissions until it costs more for the source to reduce one more unit of emissions than to buy a permit. If the permit market is perfectly competitive, then marginal abatement costs will be equal to the permit price and therefore equal across all regulated sources.

The equality of marginal abatement costs is a necessary condition for any given level of environmental quality to be achieved at the lowest overall cost, a condition known as cost-effectiveness. Putting a price on carbon was a crucial step towards market-based regulations of climate policies. Montgomery (1972) showed that market instruments may achieve their environmental objectives at lower information requirements than conventional command-and-control systems. Therefore, advocated by economists (Stavins 2010; Kerr 2000; Baumol and Oates 1975; Dales 1968), the idea of carbon trading markets becomes increasingly popular for global climate change control. The theoretical conclusion of the cost effectiveness is based upon assertion that emissions can be measured objectively and that noncompliance to environmental goals may be verified and penalized.

Unfortunately, the existence of various exogenous and endogenous inherent uncertainties violates the performance of traditional deterministic pricing concepts and raises serious concerns regarding the ability of existing carbon trading markets to fulfill the main purpose of climate change control without creating world-wide irreversible socio-economic and environmental disruptions. 
As Kyoto targets cover emissions from many individual sources, some where release processes are only partially understood, emission trading has been forced from the beginning to operate in uncertain environments. Emissions uncertainties vary in shape and duration depending on their origin (see de Jong and Walet 2004 and discussion in Ermolieva et al. 2010). In comparison to the main source of anthropogenic GHG emissions, $\mathrm{CO}_{2}$ from fuel combustion, other sources and GHG categories have much greater uncertainties and variability in measurement. Because of these, emission inventories or national systems may not be able to record the real extent or even direction of change in emission rates (Kerr 2000). A large variability of emissions may easily cause underreporting of emissions. Parties may also be inclined to underreport emissions in order to achieve compliance. Although emission trading is still only for $\mathrm{CO}_{2}$, countries participating in emission trading may bias their inventories in order to increase or redistribute the number of assigned amount units available for trading.

Sources of emissions uncertainty have been classified into the following main categories (IPCC 1997):

- Not included emission sources: There may be sources in many countries that have not yet been identified and escape inclusion in both the estimates and the list of sources excluded.

- Inadequate models of emissions estimates: Emissions estimates based on modeling of activity or processes which are believed to cause the emissions can produce large biased errors.

- Changing definitions: Emissions inventories are meant to measure anthropogenic emissions. Although in most cases it is clear whether emissions from a particular source fall within this definition, there are a number of cases when the range of accepted definitions has changed over time.

- Errors in emissions factors and activity data involves two typical uncertainties: activity data, e.g., the quantity of fossil fuel burnt, cement produced or fertilizers applied; emission factors, i.e. the emissions associated with a unit of activity. The estimate of emissions includes two source is the product of the two factors.

For all emission sources included in the Kyoto protocol, there are very different levels of uncertainties associated with the different data used to make calculations. Errors in emissions factors can have diverse causes, definitional errors, sampling errors, and measurement errors.

A comprehensive discussion of uncertainties and their implications can be found in the volume by Lieberman et al (eds.) (2007) and in Gillenwater, Sussman and Cohen 2007. Winiwarter and Muik (2010) explored inclusion of emissions uncertainties for estimating total emissions in Austria 2005. Uncertainty characteristics for each 
individual parameter were used in Monte Carlo simulations to treat non-normal distributions, dependencies between parameters, and extreme uncertainties. Figure 2 shows probability density distribution of total emissions for Austria which is most strongly influenced by the lognormal distribution of the uncertainty in $\mathrm{N}_{2} \mathrm{O}$ (in $\mathrm{CO}_{2}$ equivalent) emissions (as discussed in detail in the referred paper). This is a proof of the importance on assumptions taken for $\mathrm{N}_{2} \mathrm{O}$ emissions on the overall uncertainty of a national GHG inventory.

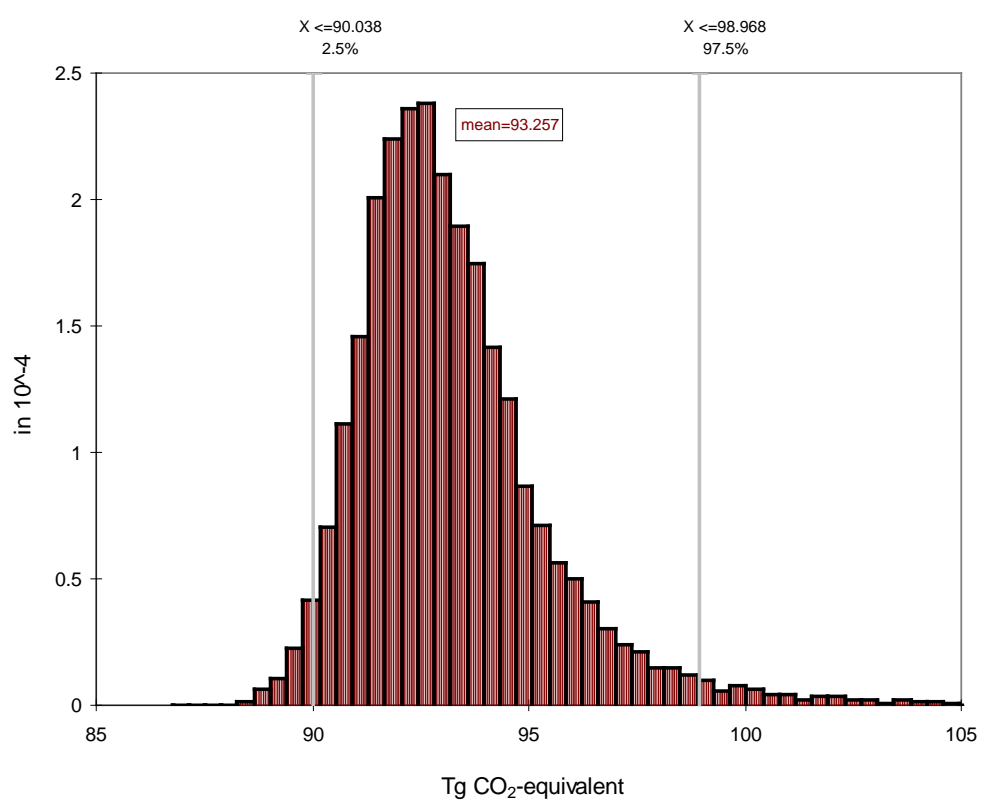

Figure 2. Probability density distribution of total emissions for Austria, 2005.

(Source: Winiwarter and Muik 2010)

Uncertainties from different sources can be analyzed under full greenhouse gas accounting (Lieberman et al., eds., 2007). Although data systems improve and the requirements for measuring emissions are being clarified, some source categories are inherently uncertain to be measured with accuracy. There will always be different levels and shapes of uncertainties in their estimates.

Some characteristics of uncertainties can be derived after revisions of the historical emissions time series following "The Good Practice Guidance" report of the IPCC (IPCC 2000). Figures 3 and 4 show by how much estimates of emissions may differ between years, for Austria and EU27. 


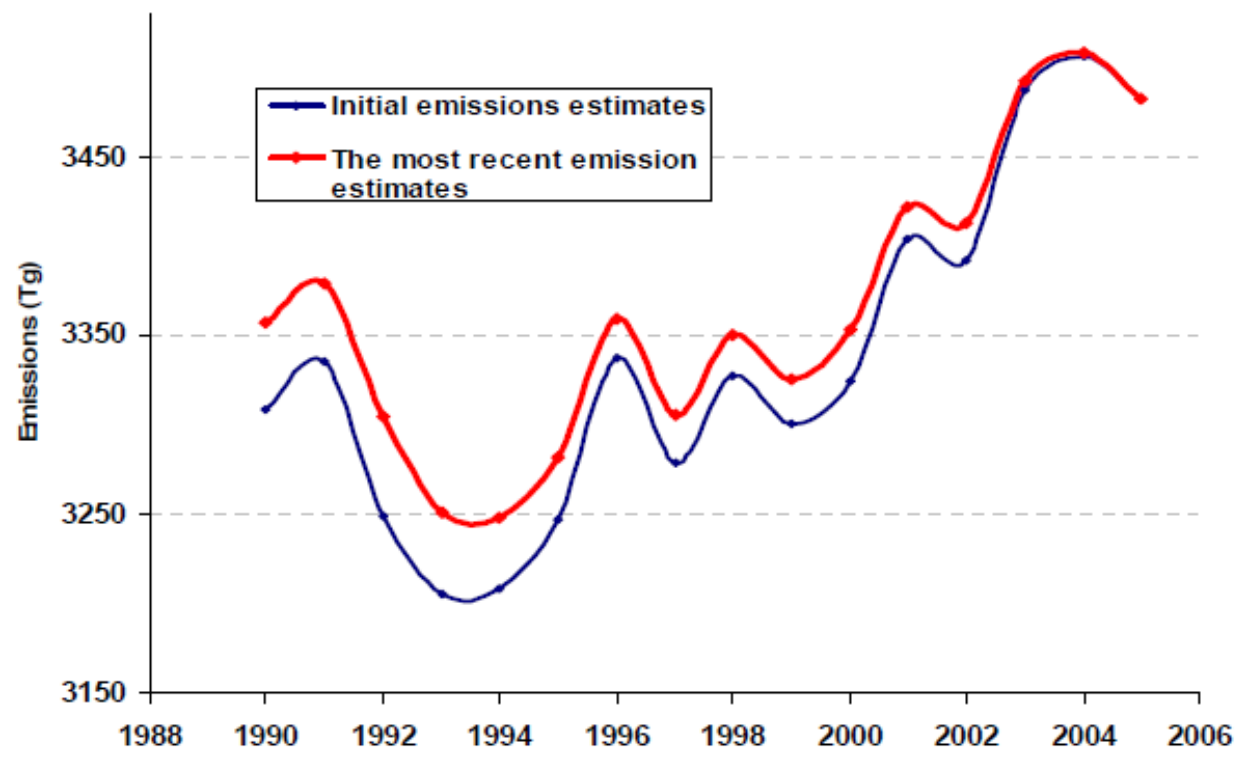

Figure 3. EU-15's $\mathrm{CO}_{2}$ emissions estimated initially and recalculated in 2005. (Source: Hamal 2010; NIR 1999-2007).

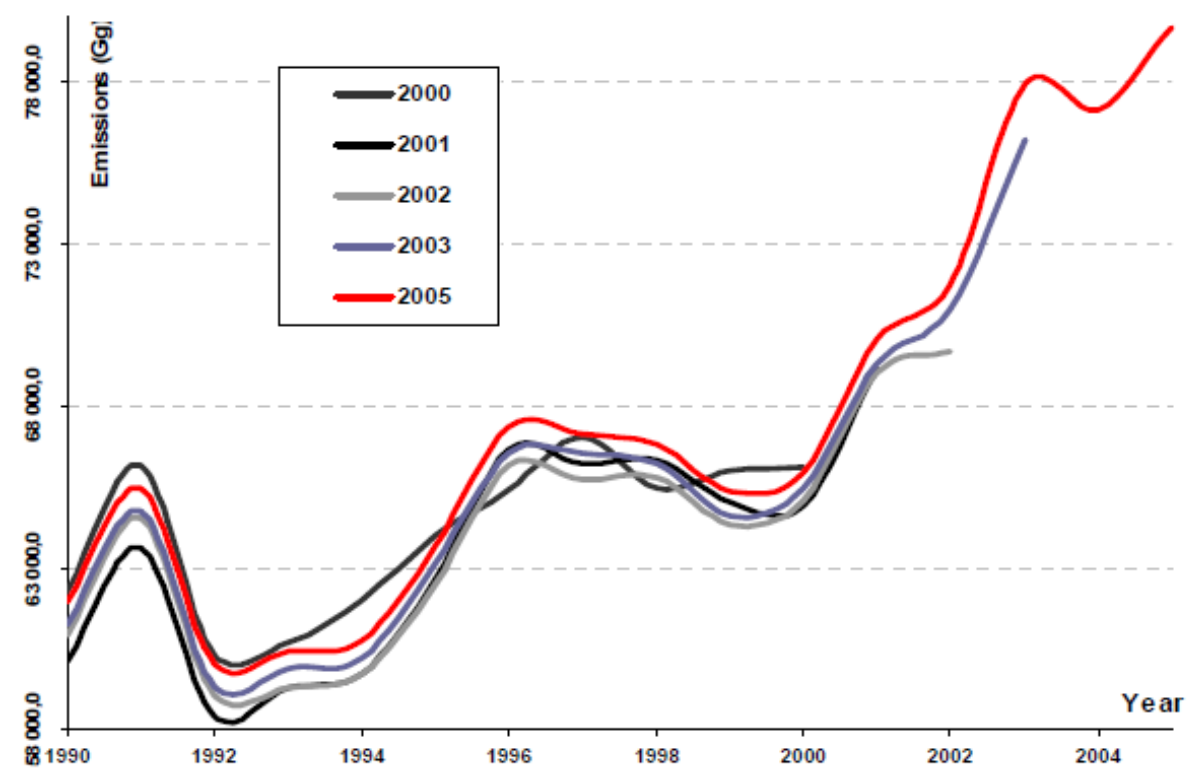

Figure 4. Austrian's emissions estimated in 2000 and recalculated in 2001, 2002, 2003 and 2005 (Hamal 2010; Austrian NIR 2002-2007).

Figures 3 and 4 indicate that with time, the differences between the initial and the adjusted estimates become larger. 


\section{Stochastic model for robust emission trading}

Our integrated robust multiagent emission trading model seeks the goal that all the parties participating in emissions trading jointly achieve individual emission targets in a cost-efficient way under safety constraints by investing in emissions abatement, uncertainty reduction and by redistributing the emission permits through trading. A key complexity is associated with asymmetric information about cost function of parties.

Emission trading affects and is being affected by emission uncertainties. In addition to asymmetric information, it implicitly contributes to reduction of other uncertainties for the two main reasons. First, trading is likely to lead towards more scrutinized emissions inventory compilation rules. Second, verifiability of trades requires that the reported emissions plus uncertainties are below the cap, therefore, trading creates incentives for parties to invest into uncertainty reduction prior to compliance. Our trading model exploits this phenomenon.

Different uncertainties differently affect emission trading causing market crashes and instabilities similar to financial markets. To limit the role of uncertainties, advocates of regulated trades argue in favor of uncertainty constraints distinguishing sources by their uncertainty levels (Godal et al. 2003, Kerr 2004). Market regulators may set restrictions on source category to be included in trading. Trading scheme may demand a Party to set source-specific targets depending on the level of uncertainty.

Following Ermolieva et al. (2010) we discuss a model which includes uncertainty and risk-adjusted regulations into emission trading schemes. The model explores conditions of market's stability towards uncertainties by imposing appropriate safety constraints to control the level of admissible uncertainty which would guarantee cost efficiency of trades and safety levels of emission reduction targets (e.g., post-Kyoto pledge targets).

These types of safety constraints are typical for pollution control, financial applications, stability regulations in the insurance industry and catastrophic risks management (see, e.g. discussion in Ermolieva et. al., 2005). In a sense, these constraints work as a probabilistic discounting mechanism which discounts the reported emissions to detectable levels overshooting uncertainty within a specified safety levels, i.e., portion of detectable emission changes.

Since the concept of safety constraints discounts emission changes to detectable levels, this provides incentives to reduce uncertainty before trading. This significantly affects the trade equilibrium state. In contrast to "black-and-white" uncertainties characterized by symmetric intervals, the proposed stochastic model aims to reduce underestimating and overestimating costs by using additional information on likelihoods of uncertainties. Figure 2 illustrates these possibilities. 
The general model is separated into two interdependent subproblems. As parties may not want to reveal information on their costs and uncertainties, they solve individual subproblems defining risk-adjusted cost functions which are used then by parties individually instead of myopic price-based evaluations.

\subsection{Party's model}

Let us denote the least costs $f_{i}\left(y_{i}\right)$ for party $i$ to comply with imposed targets with given permits $y_{i}$ and the target $K_{i}$. Formally, this function is defined by equations (1)(2). Denote the variability of reported emission $x_{i}$ as random variable $\xi_{i}\left(x_{i}, \omega_{i}\right)$, where $\omega_{i}$ is a vector of all uncertainties (scenarios) affecting emissions of party $i$. A random variable $\xi_{i}\left(x_{i}, \omega_{i}\right)$ depends, in general, on reported emissions $x_{i}$. The uncertainty $\xi_{i}$ can be reduced by investments in monitoring systems. Let us introduce for this purpose the variable $u_{i}$ associated with monitoring and other technologies that may control the variability of emissions within the desirable safety level $Q_{i}$.

The individual optimization problem can be written now as minimization of function $f_{i}\left(y_{i}\right)$ defined as the minimum of risk-adjusted expected emission reduction costs $c_{i}\left(x_{i}, \omega_{i}\right)$ and uncertainty reduction costs $d_{i}\left(u_{i}, \omega_{i}\right)$ for a given permit $y_{i}$ to be defined through dynamic trading process of Section 3.3:

$$
f_{i}\left(y_{i}\right)=\min _{x_{i} u_{i}} E\left[c_{i}\left(x_{i}, \omega\right)+d_{i}\left(u_{i}, \omega\right)\right],
$$

under quantile-based environmental safety constraints

$$
P\left[x_{i}+\xi_{i}\left(x_{i}, \omega_{i}\right) \leq K_{i}+y_{i}\right] \geq Q_{i},
$$

for all parties $i$. Here $Q_{i}$ denotes a safety level that ensures the probability that all potential emissions $x_{i}$ and uncertainties $\xi_{i}\left(x_{i}, \omega_{i}\right)$ do not exceed emission target $K_{i}$ adjusted by permits $y_{i}$. Safety level $Q_{i}$ is imposed by regulatory agency to ensure robust performance of the market. Uncertainties of cost functions $c_{i}$ and $d_{i}$ may be due to market performance, production shocks, and technological uncertainties, which are unknown in advance.

Remark 1: (Probabilistic safety constraints). Safety constraints (2) are well known in financial applications as Value-at-Risk risk indicator. They are used for safety regulation of insurance companies, reliability of engineering structures, and catastrophic risk management (Ermolieva and Ermoliev, 2005). Due to these constraints $f_{i}\left(y_{i}\right)$ and 
$F(y)$ may not be convex functions. These constraints can be in a sense equivalently substituted by using convex risk functions based on Conditional Value-at-Risk (Rockafellar and Uryasev, 2000; Ermoliev and von Winterfeldt, 2012) and using important convex stochastic approximations.

Safety constraints (2) can be also written in the following form that in the case of analytically tractable distributions is reduced to deterministic nonlinear constraints (3). Let us define quantile $z_{i}\left(x_{i}\right)$ as the minimal $z$ such that

$$
P\left[\xi_{i}\left(x_{i}, \omega_{i}\right) \leq z\right] \geq Q_{i} .
$$

Then the following equivalent constraints can be substituted for the safety constraint (2):

$$
x_{i}+u_{i} \leq K_{i}+y_{i}, u_{i} \leq z_{i}\left(x_{i}\right) .
$$

These equations show that reported emissions must undershoot targets $K_{i}$ adjusted by uncertainties of emissions $u_{i}$ and permits $y_{i}$. Equation (3) shows that safety constraints (3) induce risk-related upper bounds $z_{i}(x)$ on uncertainty intervals dependent on reported emission level $x_{i}$. Therefore, it allows to introduce risk-based undershooting of emission targets defined by “critical” quantile $z_{i}\left(x_{i}\right)$.

Functions $f_{i}\left(y_{i}\right)$ define costs of permits $y_{i}$ for parties $i=1, \ldots, n_{i}$. The main issue concerns cost-effective allocation of permits $y_{i}$ under asymmetric information about cost functions $f_{i}\left(y_{i}\right)$, i.e. solution of the following problem.

\subsection{Social planner model}

The social planner (environmental agency) needs to find the permit vector $y=\left(y_{1}, \ldots, y_{n}\right)$ or distribution of permits among parties minimizing the total or social costs

subject to

$$
F(y)=\sum_{i=1}^{n} f_{i}\left(y_{i}\right)
$$

$$
\sum_{i=1}^{n} y_{i}=0
$$

This means that the total allocation of permits remains the same as at the initial state, i.e., $\sum_{i=1}^{n}\left(K_{i}+y_{i}\right)=\sum_{i=1}^{n} K_{i}$. 
Remark 2: (Market equilibrium): Assume that $f_{i}\left(y_{i}\right)$ is continuously differentiable and strongly convex function. Then, from the Lagrangian minimization $\sum_{i=1}^{n} f_{i}\left(y_{i}\right)+\lambda \sum_{i=1}^{n} y_{i}$, a trade equilibrium is defined as the vector $y=\left(y_{1}, \ldots, y_{n}\right)$ satisfying the following equations:

$$
f_{i}^{\prime}\left(y_{i}\right)=-\lambda, \quad \lambda \sum_{i=1}^{n} y_{i}=0
$$

From condition (6) it follows that the marginal value of a permit in equilibrium is equal to a $\lambda$ same for all parties. Unlike the standard optimization models, the optimality conditions (6) cannot be directly used because parties don't reveal private information about functions $f_{i}$.

\subsection{Bilateral negotiations}

The model (4)-(5) is the standard optimization problem that could be easily solved by the social planner if private information on cost functions and uncertainties is available. The absence of information requires the development of specific decentralized optimization procedures which can be viewed as emission trading processes. Our procedures resemble bilateral negotiation process when any two parties exchange emission permits in a mutually beneficial way. Here we only briefly outline this procedure which in more detail is described for examples in (Ermolieva et al. 2010). Let $y^{k}=\left(y_{1}^{k}, \ldots, y_{n}^{k}\right)$ be the vector of emission permits after $k$ trades. Consider two parties $i$ and $j$ at step $k$ with permits $y_{i}^{k}$ and $y_{j}^{k}$. According to (6), if any two parties $i$ and $j$ have different marginal costs $f_{i}^{\prime}\left(y_{i}^{k}\right) \neq f_{j}^{\prime}\left(y_{j}^{k}\right)$, then the permit vector $y^{k}=\left(y_{1}^{k}, \ldots, y_{n}^{k}\right)$ is not cost-effective. Assume that $f_{i}^{\prime}\left(y_{i}^{k}\right)-f_{j}^{\prime}\left(y_{j}^{k}\right)<0$. Constraint (5) requires that the feasible exchange in permits does not change the total allocation of permits, i.e. it has to be such that $y_{i}^{k+1}+y_{j}^{k+1}=y_{i}^{k}+y_{j}^{k}$. If we take $y_{i}^{k+1}=y_{i}^{k}+\Delta_{k}$ and $y_{j}^{k+1}=y_{j}^{k}-\Delta_{k}, \Delta_{k}>0$, then the new feasible vector of permits $y^{k+1}$ for proper $\Delta_{k}$ reduces the total costs of parties $f_{i}\left(y_{i}^{k}\right)+f_{j}\left(y_{j}^{k}\right)$ and hence the total cost $F\left(y^{k}\right)$ because:

$$
\begin{aligned}
& F\left(y^{k+1}\right)-F\left(y^{k}\right)=f_{i}\left(y_{i}^{k+1}\right)+f_{j}\left(y_{j}^{k+1}\right)-f_{i}\left(y_{i}^{k}\right)-f_{j}\left(y_{j}^{k}\right)= \\
& \Delta_{k}\left(f_{i}^{\prime}\left(y_{i}^{k}\right)-f_{j}^{\prime}\left(y_{j}^{k}\right)\right)+o\left(\Delta_{k}\right)<0,
\end{aligned}
$$


for small $\Delta_{k}$. This equation demonstrates that bilateral trade reduces the aggregate costs for sources $i$ and $j$. From (7) for small $\Delta_{k}$ we also have

$$
f_{i}\left(y_{i}^{k+1}\right)-f_{i}\left(y_{i}^{k}\right)<f_{j}\left(y_{j}^{k}\right)-f_{j}\left(y_{j}^{k+1}\right)
$$

i.e., the new distribution of permits reduces costs of $j$ more than increasing the cost of $i$. Hence $j$ is able to compensate $i$ for the increased costs in a mutually beneficial way.

Let us summarize the trade scheme more precisely. We assume that after picking up (say at random) a pair of parties $i, j$ these parties are able to find $y_{i}^{k+1}, y_{j}^{k+1}$ minimizing

$$
f_{i}\left(y_{i}\right)+f_{j}\left(y_{j}\right)
$$

subject to constraints

$y_{i}+y_{j}=y_{i}^{k}+y_{j}^{k}, y_{i} \geq 0, y_{j} \geq 0$.

In other words, for continuously differentiable functions $f_{i}\left(y_{i}\right), f_{j}\left(y_{j}\right)$, a party $j$ that decreases emission permit by $\Delta_{k}>0$ may negotiate with $i$ such a level $\Delta_{k}$ that equalizes marginal costs, i.e., $f_{i}^{\prime}\left(y_{i}^{k}-\Delta_{k}\right)=f_{j}^{\prime}\left(y_{i}^{k}+\Delta_{k}\right)=\lambda_{k}$, where $\lambda_{k}$ can be viewed as an equilibrium price at step $k$. Let us note that price process $\lambda_{k}$ is driven endogenously by cost-minimizing decisions of meeting parties, what is fundamentally different from standard models of financial markets with exogenously given price processes.

After finding $\lambda_{k}$, the procedure is repeated with another two parties, and so on. The sequential bilateral trades can go on as long as there are two parties with different marginal costs. The bilateral exchange of emissions at each step $k$ equalizes marginal costs which define an intermediate "local" equilibrium price $\lambda_{k}$. During the process, marginal costs and prices will differ between the sequential trades, but finally the trading system converges to an equilibrium $y^{*}=\left(y_{1}^{*}, \ldots, y_{n}^{*}\right), \lambda^{*}$ with marginal costs of all parties equal to equilibrium price as in (6). The proof of the convergence is for example in (Ermolieva et al. 2010). The following section shows that the bilateral trading procedure allows to achieve the so-called core solution providing parties no incentives to trade only within a smaller number of parties. 


\subsection{A core solution}

From (8) it follows that at each step $k$ trading parties $i, j$ can redistribute joint cost by using some variables $\varphi_{i}^{k+1}$ and $\varphi_{j}^{k+1}$ reducing initial costs of these parties in mutually beneficial manner:

$f_{i}\left(y_{i}^{k+1}\right)+f_{j}\left(y_{j}^{k+1}\right)=\varphi_{i}^{k+1}+\varphi_{j}^{k+1}, \varphi_{i}^{k+1}<f_{i}\left(y_{i}^{k}\right)$,

$\varphi_{j}^{k+1}<f_{j}\left(y_{j}^{k}\right)$. Therefore at the equilibrium $y^{*}=\left(y_{1}^{*}, \ldots, y_{n}^{*}\right)$ parties will deal actually with payments $\varphi_{i}^{*}<f_{i}\left(y_{i}^{0}\right)$ such that the following equation is satisfied:

$\sum_{i=1}^{n} \varphi_{i}^{*}=\sum_{i=1}^{n} f_{i}\left(y_{i}^{*}\right):=F_{I}$

where $I=\{1, \ldots, n\}$. From this equation follows the Pareto efficiency of $\varphi^{*}=\left(\varphi_{i}^{*}\right)_{i=1, \ldots, n}$, i.e., a value $\varphi_{i}^{*}$ cannot be decreased without increasing some other value $\varphi_{j}^{*}, i \neq j$, to satisfy this equation. An important question is whether the grand coalition $I$ of parties is stable, i.e., the following equation is also satisfied:

$\sum_{i \in C} \varphi_{i}^{*} \leq F_{C}$

for any other coalition $C \subseteq I$. Accordingly, a distribution of payments $\varphi^{*}$ is a core solution if it satisfies these two equations. The bilateral trading procedure allows to find the equilibrium price $\lambda^{*}$. Namely, if function $F(y)$ is convex, then it is evident that the payment distribution $\varphi_{i}^{*}=f_{i}\left(y_{i}^{*}\right)+\lambda^{*} y_{i}^{*}$ is a core solution. In nonconvex cases, if the function $F(y)$ is globally Lipschitz continuous, then the core solution remains the same (see discussion in Evstigneev and Flam, 2001).

\subsection{Price-based scheme}

Let us compare the proposed bilateral trading scheme with a market price-based scheme. A cost-effective and environmentally safe price is a solution of the model which is dual to the basic primal model (4)-(5). The dual model derives the price $\lambda$ maximizing the following concave and, possibly, non-differentiable function

$$
g(\lambda)=\min _{y} \sum_{i=1}^{n}\left(f_{i}\left(y_{i}\right)+\lambda y_{i}\right)
$$

A given market price signal $\lambda$ decentralizes the solution of internal minimization problem into individual subproblems of parties: find solutions $y_{i}(\lambda)$ minimizing 
functions $f_{i}\left(y_{i}\right)+\lambda y_{i}$ for each $i$. In general, solutions $y_{i}(\lambda)$ don't satisfy the balance equation (5), i.e. $\sum_{i=1}^{n} y_{i}(\lambda) \neq 0$, therefore the price $\lambda$ has to be adjusted towards the desirable balance.

To ensure the balances, current $\lambda_{k}$ at time $k=0,1, \ldots$ may be adjusted proportionally to the imbalance, i.e. $g^{\prime}(\lambda)$ for continuously differentiable $g(\lambda)$ :

$$
\lambda_{k+1}=\lambda_{k}+\rho_{k} \sum_{i=1}^{n} y_{i}\left(\lambda_{k}\right)
$$

with a small step-size $\rho_{k}$. From the convergence results of quasi-gradient methods (see, e.g., discussion in Ermoliev and Wets, 1988) it follows that with $\rho_{k}=$ const $/ k$, the sequence $\lambda_{k}$ converges to the equilibrium price maximizing $g(\lambda)$. Unfortunately, this type of procedures require the private information of parties for tracking imbalances $\sum_{i=1}^{n} y_{i}\left(\lambda_{k}\right)$ for adjusting prices $\lambda_{k}, k=0,1, \ldots$. Uncertainties of markets, i.e. prices $\lambda_{k}$ , make problematic achieving cost-effective and environmentally safe allocations of permits by using price-based markets. This requires rather sophisticated mechanisms for smoothing observable random prices of market process (11) consistently with step-size $\rho_{k}$. Yet, myopic price-based markets and auctions can be organized in a vast variety of ways. The main issue is whether proposed schemes truly address asymmetric information, uncertainties of emissions and costs, and cost-effective and environmentally safe solutions.

\section{Computerized Multi-Agent Trading System: Numerical Experiments}

The available computing technology allows us to organize a Decentralized COMATS based on model (1)-(5) and bilateral trading procedure of subsection 3.3. A distributed computers network connects computers of parties with the computer of a central agency. Using a graphical user interface, parties store private information on cost functions and other characteristics of the model defined by equations (1)-(5) including specific probability distributions and scenario generators characterizing uncertainties of emissions and other parameters.

The central agency imposes market regulations in the form of safety constraints on environmental targets. Following the procedure in Section 3.3, the computer of the central agency "picks up" at random, a pair of parties $i, j$ and in anonymous manner, as it is discussed in Section 3.4, "negotiates" with computers of parties $\Delta_{k}$ and vector 
$y^{k}$ solving (9). Then, another pair of parties is picked up and the negotiations are repeated. These calculations can be easily organized without revealing private information of parties, in particular, due to distributed among different computers data of parties. The process goes on until equilibrium $\left(\lambda^{*}, y^{*}\right)$ is reached. The equilibrium solution can then be analyzed and implemented in reality using redistribution schemes discussed in Section 3.4. Therefore at the first stage COMATS evaluates equilibrium prices and permits, whereas at the second stage the equilibrium tradable permits $y^{*}$ are implemented. The information about the equilibrium price $\lambda^{*}$ identifies also the core solution (Section 3.4.) defining stable coalition of parties. It means that no party has the incentive to leave the coalition or terminate participation at any intermediate step. COMATS is of benefit both for parties and for the market. For parties, the prototype emission trading enables the analysis of the balance between robust cost-efficient and environmentally safe trades and emissions abatements. For the market, it allows to impose safety regulations ensuring stability and fair functioning without shocks.

In what follows, we discuss the implications of uncertainties on market structure by using COMATS. To analyze the performance of COMATS numerically, we use relevant to (1)-(5) data on the costs of emissions reduction from the GAINS model (Amann, 2009; Wagner and Amann, 2009; Wagner et al., 2012) for the following countries and groups of countries Australia, Canada, EU27, Japan, Norway, Russia, Ukraine, USA. The marginal cost curves (of emissions reduction as a percent of pledge targets) are displayed in Figure 5.

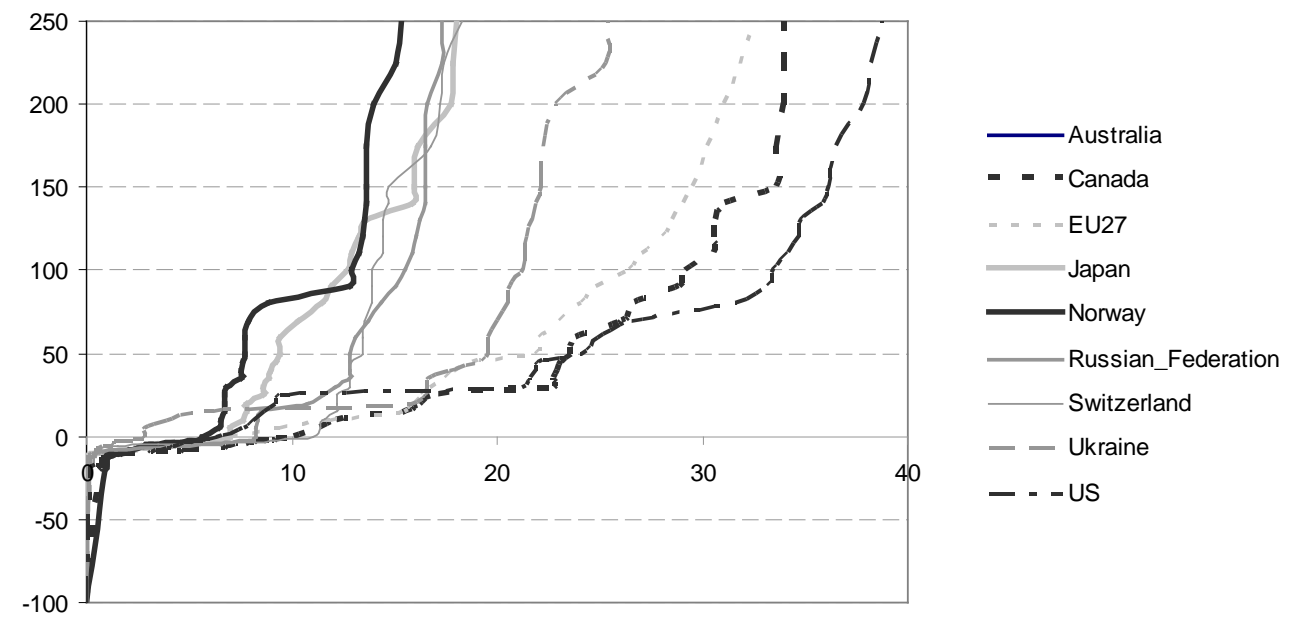

Figure 5. Marginal cost of emissions reduction as percent of pledge targets, $€$ per tC.

Table 1 shows reported emissions levels in 1990 and 2009. Projected (baseline) country-specific emissions levels in 2020 are derived from the GAINS model, and the pledge emissions reduction targets in 2020 are set according to (Wagner and Amann 2009). The data on emissions uncertainties and costs of reducing uncertainties are 
compiled from IPCC, Nahorski et al., 2007, 2010; Obersteiner et al.,2000; Godal etal.,2003, Winiwarter and Rypdal, 2001; Winiwarter, 2007; Wagner and Amann, 2009; Wagner et al., 2012. We employ uncertain emissions level in the year 2020 as percentage of the reported business as usual emissions level in 2020.

Table 1. Baseline and pledge targets (Source: Wagner and Amann 2009).

\begin{tabular}{|c|c|c|c|c|c|}
\hline & $\begin{array}{c}\text { Emissions } \\
\mathbf{1 9 9 0}\end{array}$ & $\begin{array}{c}\text { Emissions } \\
\mathbf{2 0 0 9}\end{array}$ & Baseline 2020 & $\begin{array}{c}\text { Pledge target } \\
\mathbf{2 0 2 0}\end{array}$ & $\begin{array}{c}\text { Unc. } \\
\text { (\% baseline) }\end{array}$ \\
\hline USA & 5069 & 6006 & 6641 & 4815 & 15 \\
\hline Australia & 278 & 391 & 418 & 264 & 10 \\
\hline Canada & 456 & 558 & 693 & 433 & 15 \\
\hline EU27 & 4399 & 4241 & 4677 & 4321 & 15 \\
\hline Japan & 1143 & 1270 & 1316 & 1086 & 15 \\
\hline Russia & 2499 & 1583 & 1945 & 2374 & 25 \\
\hline Ukraine & 716 & 339 & 374 & 680 & 25 \\
\hline
\end{tabular}

Table 2. Trades ignoring uncertainty.

\begin{tabular}{|c|c|c|c|c|c|c|c|}
\hline & USA & Austr & Can & EU27 & Japan & Rus & Ukr \\
\hline $\begin{array}{l}\text { Em opt (MtC) } \\
\text { Unc opt } \\
\text { Trades opt } \\
\text { Marginal cost (€ per tC) }\end{array}$ & $\begin{array}{c}5017 \\
0 \\
202 \\
13\end{array}$ & $\begin{array}{c}397 \\
0 \\
133 \\
13\end{array}$ & $\begin{array}{c}643 \\
0 \\
210 \\
13\end{array}$ & $\begin{array}{c}4401 \\
0 \\
80 \\
13\end{array}$ & $\begin{array}{c}1274 \\
0 \\
188 \\
13\end{array}$ & $\begin{array}{c}1900 \\
0 \\
-474 \\
13\end{array}$ & $\begin{array}{c}340 \\
0 \\
-340 \\
13\end{array}$ \\
\hline \multicolumn{8}{|l|}{$\begin{array}{l}\text { Costs after trades } \\
\text { (Million } €)\end{array}$} \\
\hline $\begin{array}{c}\text { Em reduction } \\
\text { Unc reduction } \\
\text { Trades }\end{array}$ & $\begin{array}{c}11091 \\
0 \\
2596\end{array}$ & $\begin{array}{c}261 \\
0 \\
1637\end{array}$ & $\begin{array}{c}650 \\
0 \\
2540\end{array}$ & $\begin{array}{c}2969 \\
0 \\
958\end{array}$ & $\begin{array}{c}392 \\
0 \\
2231\end{array}$ & $\begin{array}{c}1270 \\
0 \\
-5739\end{array}$ & $\begin{array}{c}200 \\
0 \\
-4046\end{array}$ \\
\hline Total (core) & 13687 & 1898 & 3190 & 3927 & 2622 & -4469 & -3845 \\
\hline \multicolumn{8}{|c|}{$\begin{array}{l}\text { Costs for mitigation without } \\
\text { trades } \\
\text { (Million } €)\end{array}$} \\
\hline $\begin{array}{l}\text { Em reduction } \\
\text { Unc reduction }\end{array}$ & $\begin{array}{c}13839 \\
0\end{array}$ & $\begin{array}{c}16992 \\
0\end{array}$ & $\begin{array}{c}29341 \\
0\end{array}$ & $\begin{array}{c}4221 \\
0\end{array}$ & $\begin{array}{c}23959 \\
0\end{array}$ & $\begin{array}{l}0 \\
0\end{array}$ & $\begin{array}{l}0 \\
0\end{array}$ \\
\hline Total & 13839 & 16992 & 29341 & 4221 & 23959 & 0 & 0 \\
\hline $\begin{array}{l}\text { Financial advantages } \\
\text { of trading } \\
\text { Total profits }\end{array}$ & 152 & 15095 & 26152 & 294 & 21336 & 4469 & $\begin{array}{r}3845 \\
71342\end{array}$ \\
\hline
\end{tabular}

Table 2 illustrates the results of emission permit trades among seven countries ignoring uncertainties. In equilibrium, the cost of reducing reported emissions (also optimal price of emissions permit) is about $€ 13$ per $\mathrm{tC}$, which is consistent with existing market trends (www.pointcarbon.com). Total costs of emissions reduction to targeted levels without 
trades are defined by "Costs for mitigation without trades", while "Costs after trades" stands for optimal costs for emissions abatements and trades. Financial advantages of trading are estimated by comparing the two alternatives. Optimal total ("core”) costs of parties are calculated according to formula (10). In these experiments, no emission uncertainties are included, therefore no costs are spent on uncertainties reduction, i.e. “unc. reduction” equals 0. Russia and Ukraine are major permits' sellers (negative values of trades), and it is explained by their emissions levels in 2020, which are lower than pledge targets.

Table 3. Trades with uncertainty.

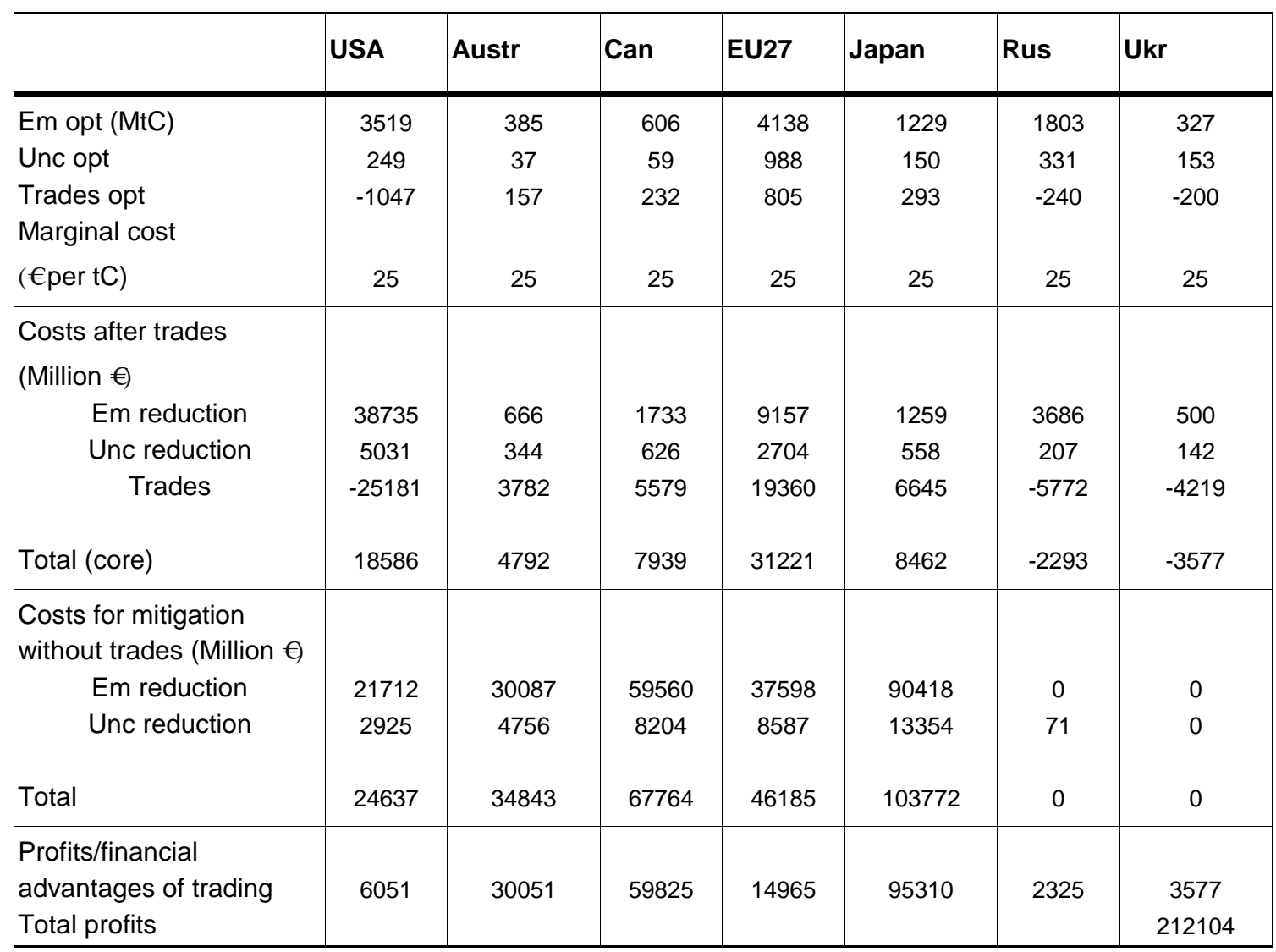

The results of a scenario involving uncertainties are presented in Table 3. Optimal marginal cost of reducing unit reported emissions equals the cost of reducing unit uncertain emissions and is about $€ 25$ per $\mathrm{tC}$, which is almost twice higher than in the case when uncertainties are not included in calculations. The higher costs are due to more abatements as the uncertainties are now accounted for in the verification of targets compliance according to (2). Optimal marginal costs also increase because in this case Russia and Ukraine invest in uncertainties reduction and therefore can offer less traded permits at zero price than in the scenario without uncertainties. 
Table 4. Trades with uncertainty, US excluded.

\begin{tabular}{|c|c|c|c|c|c|c|c|}
\hline & $\begin{array}{c}\text { USA } \\
\text { (excluded) }\end{array}$ & Austr & Can & EU27 & Japan & Rus & Ukr \\
\hline Em opt & 3519 & 336 & 518 & 3589 & 1165 & 1577 & 293 \\
\hline Unc opt & 249 & 35 & 58 & 989 & 154 & 295 & 149 \\
\hline Trades opt & -1047 & 107 & 142 & 257 & 233 & -502 & -237 \\
\hline Marginal cost & 25 & 75 & 75 & 75 & 75 & 75 & 75 \\
\hline \multicolumn{8}{|l|}{$\begin{array}{l}\text { Costs after trades } \\
(\text { Million } €)\end{array}$} \\
\hline Em reduction & 38735 & 3860 & 8702 & 49011 & 6587 & 19884 & 3040 \\
\hline Unc reduction & 5031 & 1148 & 2003 & 8359 & 1680 & 690 & 356 \\
\hline Trades & -25181 & 7974 & 10665 & 19233 & 17556 & -37469 & -17901 \\
\hline Total (core) & 18586 & 12983 & 21370 & 76603 & 25823 & -16895 & -14505 \\
\hline \multicolumn{8}{|l|}{$\begin{array}{l}\text { Costs for mitigation } \\
\text { without trades (Million } € \text { ) }\end{array}$} \\
\hline Em reduction & 21712 & 30087 & 59560 & 37598 & 90418 & 71 & 0 \\
\hline Unc reduction & 2925 & 4756 & 8204 & 8587 & 13354 & -38 & 0 \\
\hline Total & 24637 & 34843 & 67764 & 46185 & 103772 & 33 & 0 \\
\hline $\begin{array}{l}\text { Profits/financial } \\
\text { advantages of trading } \\
\text { Total profits }\end{array}$ & 6051 & 21860 & 46394 & -30417 & 77949 & 16928 & $\begin{array}{c}16996 \\
153270\end{array}$ \\
\hline
\end{tabular}

In the scenario when uncertainties are explicitly included in the trading, the US turns to a permit supplier. This is due to two reasons. First, the US marginal cost curve is a flatter slope than other countries. Second, because the assumed uncertainties in the US are relatively low. In this scenario, as Table 3 also shows, Russia and Ukraine invest in monitoring to reduce the uncertainties around targets and, therefore, supply less permits than in the case without uncertainties. Although the results have illustrative purpose, the conclusion is that the equilibrium price of emissions permits highly depend on uncertainties.

In both scenarios, with and without uncertainties treatment, the "core" solution derived at equilibrium makes all parties better off. Total profits from trades equal about 71.3 and 213 Billion $€$, in case without and with uncertainty, respectively, which is $19 \%$ and $23 \%$ higher, for without and with uncertainties, than in the situation without trading.

Distortions to the emissions trading system may be caused by individual characteristics of market players. For example, as Table 4 indicates, participation of the US in EU ETS is of major benefit. The market without the US has much higher marginal cost (if compared to Table 3) due to rather steep cost curves and high demands in permits (except for Russian and Ukraine) of the other traders. 


\section{Concluding Remarks}

We discussed the gap existing between the theoretical conclusions about cost-efficiency of emission trading schemes and the reality. In theory, the emission price of tradable allowances should establish the marginal cost of emissions reductions to meet the cap. In reality, the existence of various exogenous and endogenous inherent uncertainties violates the performance of traditional deterministic pricing concepts. Recent market crashes raised serious concerns regarding the ability of existing carbon trading markets to fulfill the main purpose of the climate change control. Lessons learned from the existing emission trading schemes point out to the need for market's safety regulations smoothing its performance.

The proposed multi-agent approach integrating regulations of carbon emissions and uncertainties with redistribution of emissions through emission trading under safety constraints allows us to design a computerized multiagent trading system that may function as a prototype of a robust emission trading market. The model explores conditions of market's stability with respect to uncertainty by using appropriate safety constraints controlling verifiable uncertainty reductions which would guarantee cost efficiency of trades and safety levels of emission reduction targets (e.g., post-Kyoto pledge targets). We illustrate functioning of the robust market with numerical results involving such countries as the US, Australia, Canada, Japan, EU27, Russia, Ukraine, etc. Explicit treatment of uncertainties may significantly affect portfolios of technological and trade policies, market prices and change the market structure. We conclude also that exclusion or inclusion of additional players may have dramatic effects on the market. 


\section{References}

Amann, M. (2009) Integrated assessment tools: The Greenhouse and Air Pollution Interactions and Synergies (GAINS) model. Pollution Atmospherique Special Issue:73-76.

Baumol, W., Oates, W. (1975) The theory of environmental policy. Cambridge University Press, Cambridge, New York, Sydney.

Betz, R., Sato, M. (2006) Emissions trading: lessons learnt from the 1st phase of the EU ETS and prospects for the 2nd phase. Climate Policy 6:351-359.

Dales, J. H. (1968) Pollution property and prices: an essena in policy-making and economics. University of Toronto Press.

De Jong, C., Walet, K. (eds) (2004) A guide for emission trading: Risk management and business implications. London: Risk Books.

Ermolieva, T., Ermoliev, Y. (2005) Catastrophic risk management: Flood and seismic risks case studies. In: Wallace SW, Ziemba WT (eds) Applications of stochastic programming. MPSSIAM Series on Optimization, Philadelphia, PA, USA.

Ermolieva, T., Ermoliev, Y., Fischer, G., Jonas, M., Makowski, M. (2010a) Cost effective and environmentally safe emission trading under uncertainty. In: Marti K, Ermoliev Y, Makowski M (eds) Coping with uncertainty: Robust solutions. Springer-Verlag, Heidelberg, Germany, 79-99.

Ermolieva, T., Ermoliev, Y., Fischer, G., Jonas, M., Makowski, M., Wagner, F. (2010b) Carbon emission trading and carbon taxes under uncertainties. Climatic Change 103(1-2).

Ermoliev, Y., von Winterfeldt, D. (2012) Systemic risk and security management. In: Ermoliev Y, Makowski M, Marti K (eds) Managing Safety of Heterogeneous Systems. Springer-Verlag, Berlin, Germany, pp. 19-49.

Ermoliev, Y., Michalevich, M., Nentjes, A. (2000) Markets for tradable emission and ambient permits: A dynamic approach. Environ Res Econ 15:39-56.

Ermoliev, Y., Wets, R. (eds) (1988) Numerical techniques of stochastic optimization. Computational Mathematics, Berlin, Springer Verlag.

Evstigneev, I., Flam, S. (2001) Sharing nonconvex cost. J Global Optimization 20:257-271.

Gillenwater M., Sussman F., Cohen J. (2007) Practical policy applications of uncertainty analysis for national greenhouse gas inventories. In: Lieberman D, Jonas J, Nahorski Z, Nilson S (eds) Accounting for climate change: Uncertainty in Greenhouse Gas inventories verification, compliance, and trading. Springer Verlag.

Godal, O., Ermoliev, Y., Klassen, G., Obersteiner, M. (2003) Carbon trading with imperfectly observable emissions. Environ Res Econ 25:151-169.

Hamal K. (2010) Reporting GHG emissions: Change in uncertainty and its relevance for detection of emission changes. IIASA IR-10-003, International Institute for Applied Systems Analysis, Laxenburg, Austria.

IPCC. (2000) Good practice guidance and uncertainty management in national greenhouse gas inventories. Intergovernmental Panel on Climate Change, National Greenhouse Gas Inventories Programme, Hayama.

Kerr, S. (ed) (2000) Global emissions trading: Key issues for industrialized countries. Edward Elgar, Cheltenham, UK, Northampton, MA, US. 
Lieberman, D., Jonas, M., Nahorski, Z., Nilsson, S. (2007) Accounting for Climate Change: Uncertainty in Greenhouse Gas Inventories-Verification, Compliance, and Trading. Springer Verlag, Berlin, Germany.

McCain, R. (2010) Game Theory: A Nontechnical Introduction to the Analysis of Strategy. World Scientific Publishing, ISBN-13 978-981-4289-65-8.

Milgrom, P., Roberts,, J. (1986) Price and advertising signals of product quality. J. of Polit Econ 94: 795-781.

Montgomery, D.W. (1972) Markets in licenses and efficient pollution control programs. J. Public Econ 75:273-291.

Nahorski, Z., Horabik, J., Jonas, M. (2007) Compliance and emissions trading under the Kyoto Protocol: Rules for uncertain inventories. In: Lieberman, D., Jonas, M., Nahorski, Z., Nilsson, S., (eds) Accounting for Climate Change: Uncertainty in Greenhouse Gas inventories - verification, compliance, and trading. Springer Verlag, 119-138.

Nahorski, Z., Stanczak, J., Palka, P. (2010) Multi-agent approach to simulation of the greenhouse gases emission permits market. In: Proceedings of the 3rd International Workshop on Uncertainty in Greenhouse Gas Inventories, 22-24 September 2010, Lvov, Ukraine, 183-195.

Obersteiner, M., Ermoliev, Y., Gluck, M., Jonas, M., Nilsson, S., Shvidenko, A. (2000) Avoiding a lemons market by including uncertainty in the Kyoto Protocol: Same mechanism - improved rules. Interim Report IR-00-043. International Institute for Applied Systems Analysis, Laxenburg, Austria.

Rockafellar ,T., Uryasev, S. (2000) Optimization of conditional Value at Risk. The Journal of Risk 2/3:21-41.

Roos, J. (2011) EU emissions trading triggered dash for coal. The Breakthrough Institute, http://breakthrougheurope.org/

Stavins R (2010) The problem of the Commons: Still unsettled after 100 years. Discussion paper RFF DP 10-46. Resources for the Future. Washington DC, www.rff.org.

Stikkelman, R., Dijkema, G., Chappin, E. (2010) Emissions trading fails to reduce $\mathrm{CO}_{2}$ emissions. Delft University of Technology. Faculty of Technology, Policy and Management.

Wagner, F., Amann, M. (2009) GAINS contribution to ETMA request \#2B -v1, International Institute for Applied Systems Analysis (IIASA).

Wagner F, Amann M, Borken-Kleefeld J, Cofala J, Höglund-Isaksson L, Purohit P, Rafaj P, Schöpp W, Winiwarter W (2012) Sectoral marginal abatement cost curves: implications for mitigation pledges and air pollution co-benefits for Annex I countries. Sustainability Science 7:169-184.

Winiwarter, W., Rypdal, K. (2001) Assessing the uncertainty associated with national greenhouse gas emission inventories: a case study for Austria. Atmos Environ 35:54255440 .

Winiwarter, W. (2007) National Greenhouse Gas Inventories: Understanding Uncertainties versus Potential for Improving Reliability. Water Air Soil Pollut 7:443-450, DOI 10.1007/s11267-006-9117-3.

Winiwarter, W., Muik, B. (2010) Statistical dependence in input data of national greenhouse gas inventories: effects on the overall inventory uncertainty. Climatic Change 103:19-36, DOI 10.1007/s10584-010-9921-7. 